\title{
Rotasyon kontrollü Wilson-Cowan nöron modeli ve donanım gerçekleştirimi
}

\author{
Rotation-controlled Wilson-Cowan neuron model and its hardware
}

\author{
Nimet Korkmaz ${ }^{1, *}$ \\ 1,* Kayseri Üniversitesi, Elektrik-Elektronik Mühendisliği Bölümü, 38280, Kayseri, Türkiye
}

\section{Özet}

Canlı vücudundaki iletişim ağının temel elemanı olan nöronların karakteristik dinamiklerini açıklamak için, doğrusal olmayan fonksiyon tanımlamalarından yararlanılarak çeşitli biyolojik nöron modelleri tanımlanmıştır. $\mathrm{Bu}$ modellerin analizlerinde, doğrusal olmayan sistemlerin analizlerinde kullanılan çözüm yöntemlerinden sıklıkla yararlanılmaktadır. Son yıllarda doğrusal olmayan sistemleri konu alan çalışmaların bir kısmında rotasyonlu çeker yapıları ile karşılaşılmaktadır. $\mathrm{Bu}$ çalışmada, literatürde uyarıcı ve engelleyici sinaps yapılarını tanımlamada etkin kullanılan Wilson Cowan (WC) nöron modeline Euler Rotasyon Teoremi'nin uygulanması ile elde edilen rotasyonlu çekerin faz kontrolünün sağlanması amaçlanmıştır. Ayrıca, gerçek zamanlı işaretlere ihtiyaç duyulabilecek çalışmalarda kullanılabilirliğinin gösterilmesi amacı ile rotasyon kontrollü W-C nöron modelinin FPGA (Field Programmable Gate Array) tabanlı donanım gerçekleştirim çalışması da yapılmıştır. Yapılan nümerik analizler ile rotasyon kontrollü $\mathrm{W}-\mathrm{C}$ nöron modelinin çeker yapısının başarılı bir şekilde kontrol edilebildiği görülmüştür. Öte yandan deneysel gerçekleştirim çalışmaları ile biyolojiden esinlenilerek tasarlanan ve elektronik ekipmanlarla taklit edilen sistemler için alternatif bir çalışma kaydedilmiştir.

Anahtar kelimeler: Wilson-Cowan nöron modeli, Uyarıcı ve engelleyici sinaps, Euler rotasyon teoremi, Doğrusal olmayan sistemler, Alan programlanabilir kap1 dizisi (FPGA)

\section{Giriş}

Merkezi sinir sisteminin temel fonksiyonel birimleri nöronlardır. Nöronlar soma, dendrit ve akson olmak üzere temel üç kısımdan oluşmaktadır. Nöron çekirdeğini ve çekirdekçiğini içeren kısım somadır. Soma içerisinden çıkan k1sa uzantılara dendirt adı verilir. Akson ise nöron gövdesinden çıkan tek bir uzun yapıdır ve nöronlar arası bilgi transferi sürecinde önemli bir rolü vardır. Nöronlar arasında meydana gelen bilgi iletim süreci elektriksel sinyallerle gerçekleşmektedir. Nöronların hücre zarında meydana gelen iyonik konsantrasyon değişimi, bir akım indüklemekte ve bu akım hücre zarında potansiyel oluşmasına sebep olmaktadır. Oluşan bu potansiyel aksiyon potansiyeli olarak adlandırılmaktadır. Aksiyon potansiyelinin oluşumu sadece iyonik konsantrasyon değişimine bağlı olmayıp; nörona harici uygulanan akımlara ve diğer nöronlardan gelen

\begin{abstract}
Various biological neuron models have been defined by using nonlinear function definitions in order to explain the characteristic dynamics of neurons that are the basic elements of the communication network in the living body. In the analysis of these models, the solution methods used in the analysis of nonlinear systems are frequently used. In recent years, some of the studies about nonlinear systems have been encountered with the rotational attractor structures. In this study, it is aimed to provide phase control of the rotational attractor obtained by applying the Euler Rotation Theorem to the Wilson Cowan (W-C) neuron model that is used effectively in the literature to define excitatory and inhibitory synapse structures. In addition, the FPGA (Field Programmable Gate Array)-based hardware implementation study of the rotation-controlled $\mathrm{W}-\mathrm{C}$ neuron model have also been carried out in order to see its usability in studies required to the real-time signals. With the numerical analyzes, it has been seen that the attractor structure of the rotation-controlled W-C neuron model can be controlled successfully. On the other hand, an alternative study has been reported for the systems designed by inspiring the biology and emulated with electronic equipment
\end{abstract}

Keywords: Wilson-Cowan neuron model, Excitatory and inhibitory synapse, Euler rotation theorem, Nonlinear systems, Field programmable gate array (FPGA).

etkilere de bağlıdır. Nöronlar arası bağlantı noktalarını niteleyen ve nöronlar arasında bilgi iletiminden sorumlu olan yapılar sinapslardır. Bir nöron etkileşimli olduğu diğer nöronlarla sinaps yapıları aracılığı ile haberleşir. Sinaps yapıları elektriksel ve kimyasal sinaps olmak üzere iki tiptedir: Elektriksel sinapsta doğrudan iletim söz konusudur ve iletişim hızlıdır. Kimyasal sinapta ise; presinaptik uçtan salgılanan nörotransmitterler postsinaptik uçtaki reseptörlere bağlanır. Nöronlar arası sinyal İletimi gerçekleştikten sonra, sinaptik boşlukta nörotransmitter maddeler enzimler tarafından parçalanır ve nöron tarafından tekrar hücre içine alınır. Akson ucundan salgılanan nörotransmitter maddelerin, komşu hücrenin zarında depolarizasyona neden olması ve bilgi işaretinin bir sonraki nörona iletilmesi "Uyarıcı (excitatory) sinaps" olarak tanımlanır. Akson ucundan salgilanan nörotransmitter maddelerin, hücre

\footnotetext{
* Sorumlu yazar / Corresponding author, e-posta / e-mail: nimetkorkmaz@kayseri.edu.tr (N. Korkmaz) Geliş / Recieved: 29.09.2021 Kabul/ Accepted: 14.12.2021 Yayımlanma/Published: 14.01.2022 doi: 10.28948/ngmuh.1002174
} 
zarının polarizasyonunu artırarak (hiperpolarizasyon) bilgi işaretinin nörondan geçişini durdurması ise "engelleyici (inhibitory) sinaps" olarak tanımlanmaktadır. Uyarıcı ve engelleyici etkilerin toplamı postsinaptik nöronda ateşlemeyi kolaylaştırır ya da zorlaştırır [1].

Canlı vücudunda gerçekleşen hücre zarı potansiyeli üretimi ve nöronlar arası işaret işleme gibi biyolojik süreçler, biyolojik nöron modelleri ile başarılı şekilde modellenebilmektedir. Bu modellerden en kapsamlı olanı Hodgkin-Huxley $(\mathrm{H}-\mathrm{H})$ nöron modelidir [2]. Hücre zarında meydana gelen iyonik konsantrasyon değişimi ve voltaj kapılarının açılıp kapanma olasılıkları, bu modelle detaylı olarak tanımlanmıştır. Modelin kapsamlı olması sebebiyle, $\mathrm{H}-\mathrm{H}$ nöron modeli basitleştirilerek FitzHugh-Nagumo (FHN) nöron modeli elde edilmiştir [3]. FHN nöron modeli basit bir model olması avantajına sahipken, modelin farklı nöron dinamiklerini sergilemedeki eksikliği nedeniyle Hindmarsh-Rose (H-R) nöron modeli geliştirilmiştir [4]. H$\mathrm{R}$ nöron modeli farklı nöral dinamikleri sergileyebilmesinin yanı sıra; elektriksel ve kimyasal kuplajlama sürecini başarılı bir şekilde tanımlayabilmesi sebebi ile nöral senkronizasyon çalışmalarında tercih edilmektedir. Yaklaşık yirmi nöral dinamiği sergileyebilmesi ve basit bir tanımlamaya sahip olması yönüyle öne çıkan Izhikevich nöron modeli de literatürde sıklıkla çalışılmaktadır [5]. Bahsedilen ve benzeri pek çok model literatürde mevcuttur ve bu modellerin her birinin kendisine özgü avantaj ve dezavantajları vardır. Bu çalışmada ise Wilson- Cowan (W-C) nöron modeli üzerinde durulacaktır. Basit uyarıcı ve engelleyici nöron popülâsyonları arasındaki etkileşimin dinamiklerini açıklama açısından öne çıkan yapı; W-C nöron modelidir [6]. $\mathrm{Bu}$ model nöral popülasyon modellemede siklıkla kullanılmaktadır. Modellenen nöronlar basit yapıda olduklarından, model sadece elementer limit döngü davranışı sergilemektedir. Modelin temel amacı bir nöron popülâsyonundaki uyarıcı ya da engelleyici alt tiplerinin aktivitelerini ölçmektir. Bu sebeple, W-C nöronal modeli; nöral ağ yapılarının taklidine ihtiyaç duyulan epilepsi nöbetlerinin tespiti, fMRI görüntüleme, görüntü ve ses işleme ve merkezi desen üreteci gibi alanlara konu olan bir modeldir [7-9].

Biyolojik nöron modellerinin matematiksel analizlerinde, doğrusal olmayan sistemlerin analizlerinde kullanılan çözümlerinden sıklıkla yararlanılmaktadır. Örneğin, osilatörler ya da kaotik osilatör yapılarının analizleri için kullanılan kararlılık ve kontrol teoremleri gibi yöntemler biyolojik nöron modellerine de başarılı bir şekilde uygulanabilmektedir [10]. Son yıllarda doğrusal olmayan sistemleri konu alan çalışmaların bir kısmında rotasyonlu çeker yapıları ile karşılaşılmaktadır. Bu rotasyonlu çekerler; akışkanlar dinamiğinde, lazer sistemlerinde, kaotik sistemlerde, biyolojik sistemlerde ve nöral sistemlerde gözlemlenmiştir [11-13]. Literatürde kaotik sistemlerde gözlemlenen rotasyonlu çekerlerin modellenmesi için Euler Rotasyon Teoremi'nden yararlanılmıştır [14-15]. Teoremin uygulanabilirliğinin görülmesi açısından, rotasyonlu sistemlerin donanım gerçekleştirimlerini ele alan çalışmalar da yapılmıştır. Kaotik sistemlere uygulanan bu teorem, nöral sistemlerde karşılaşılan rotasyonlu çekerlerin modellenmesi için de kullanılabilir. Bu kapsamda, bu çalışmada literatürde uyarıcı ve engelleyici sinaps yapılarını tanımlamada etkin kullanılan W-C nöron modeline Euler Rotasyon Teoremi'nin uygulanması ile elde edilen rotasyonlu çekerin faz kontrolünün sağlanması amaçlanmıştır. Ayrıca, gerçek zamanlı işaretlere ihtiyaç duyulabilecek çalışmalarda kullanılabilirliğinin gösterilmesi amacı ile çeker faz açısı kontrol edilen W-C nöron modelinin donanım gerçekleştirim çalışmaları da yapılmıştır. Donanım gerçekleştiriminde; düşük güç tüketimi, donanım maliyeti, hassas parametre ayarı yapabilme imkânı ve programlanabilirlik özelliklerini bir arada bulunduran alan programlanabilir kapı dizisi (Field Programmable Gate Array-FPGA) elemanı kullanılmıştır.

$\mathrm{Bu}$ kapsamda Wilson-Cowan nöron modelinin esasları ve modelin nümerik simülasyonu ele alındıktan sonra; modele rotasyon dönüşümün uygulanması ile elde edilen sonuçlar Bölüm 2'de sunulacaktır. FPGA tabanlı gerçekleştirime dair ayrıntılar ve deneysel gerçekleştirim sonuçları ise Bölüm 4'te verilecektir. Sistemin gerçekleştirimi sonrasındaki alan kullanımı ve sentez sonuçları ile ilgili ayrıntılar ve elde edilen çıktılar son bölümde tartışılacaktır.

\section{Rotasyon kontrollü Wilson-Cowan nöron modeli}

Wilson-Cowan (W-C) nöron modeli; bir nöral popülasyonunun ortalama aksiyon potansiyeli frekansını, sürekli zamanın bir fonksiyonu olarak tanımlar. Modelin temel varsayımı, beyin aktivitesinin uyarıcı ve engelleyici popülasyonlar arasındaki etkileşimlerle tanımlanabileceğidir. Bu nedenle W-C nöron modelinin durum değişkenleri, sırasıyla "Uyarıcı (Excitatory)" ve "engelleyici (Inhibitory)" artı̧̧ oranları olan 'E' ve 'I' parametreleridir. Bilinen nöroanatomiye dayanarak, Wilson ve Cowan, bireysel hücreler arasında rastgele ve yoğun bir bağlantı olduğunu ve ağdaki herhangi iki hücre arasında en az bir bağlantıya imkân sağlandığını varsaymışlardır. Wilson ve Cowan, lokalize bir kortikal alanda zamansal dinamikleri araştırmak için 1972 tarihli orijinal makalelerinde uzamsal etkileşimleri ihmal etmiş̧lerdir [6]. Daha sonra modellerini 1973 tarihli çalışmalarında uzamsal olarak dağılmış sinir popülasyonlarına genişletmiş ve kortikal ve talamik doku tabakalarını modellemişlerdir [16]. 1999'da Wilson, kortikal yapıları temsil eden ' $E$ ' ve 'I' popülasyonlarının lokalize kümelerinden oluşan ve kortikal dokunun işbirlikçi davranışını tanımlayan basitleştirilmiş matematiksel bir nöral form geliştirmiştir [17]. Son olarak, modelin en basit hali olan ve popülasyon ateşlenme oranını pozisyondan bağımsız olarak homojen bir korteks şeklinde modelleyen Denklem (1)'deki model türetilmiştir [18]:

$$
\begin{aligned}
& \tau_{E} \frac{d E}{d t}=-E+f_{E}\left(c_{E E} E-c_{I E} I+P\right) \\
& \tau_{I} \frac{d I}{d t}=-I+f_{I}\left(c_{E I} E-c_{I I} I+Q\right)
\end{aligned}
$$

Burada ' $E$ ' ve 'I' uyarıcı ve engelleyici ateşlenme oranlarıdır. ' $\tau_{\mathrm{E}}$ ' ve ' $\tau_{\mathrm{I}}$ ' sirasıyla ' $\mathrm{E}$ ' ve 'I' değişkenlerinin zaman sabitleridir. ' $c_{\mathrm{EE}}, \mathrm{c}_{\mathrm{IE}}, \mathrm{c}_{\mathrm{EI}}$ ve $\mathrm{c}_{\mathrm{II}}$ ' Şekil 1'de görüldüğü gibi sinaptik kuplajlama ağırlıklarıdır. Burada zaman 
sabitleri $\tau_{\mathrm{E}}=1$ ve $\tau_{\mathrm{I}}=1$ değerlerine ve sinaptik ağırlıklar sirasıyla $\left(c_{\mathrm{EE}}, \quad c_{\mathrm{IE}}, \quad c_{\mathrm{EI}}, \quad c_{\mathrm{II}}\right)=(5,5,5,3)$ değerlerine ayarlanmıştır. $\mathrm{Bu}$ parametre değerleri ile $\Delta \mathrm{h}=0.01 \mathrm{ad} ı \mathrm{~m}$ aralıklı Euler ayıklaştırma yöntemi kullanılarak yapılan ve maksimum iterasyon sayısının $\mathrm{N}=5000$ alındığı nümerik simülasyona ait sonuçlar Şekil 2'de sunulmaktadır. Kartezyen Koordinat Sistemi'nde $(x, y, z)$ noktaları ile tanımlanan bir sistem, rotasyon dönüşümü sonrasında, ( $\hat{x}, \hat{y}, \hat{z}$ ) olmak üzere alternatif bir küme ile tanımlanabilir.

' $\mathrm{fE}$ ' ve ' $\mathrm{f}_{\mathrm{I}}$ ' doğrusal olmayan özdeş fonksiyonlardır. Literatürde Wilson-Cowan nöron modelinin ele alındığ çalışmaların genelinde ilgili doğrusal olmayan fonksiyonlar Denklem (2a)'da verilen fonksiyonla tanımlanırken, bu fonksiyon yerine Denklem (2b) ve Denklem (2c)'deki alternatif tanımlamaların kullanıldığı çalışmalar da literatürde mevcuttur [19-21]. Bu çalışmada ' $\mathrm{f}_{\mathrm{E}}$ ' ve ' $\mathrm{f}_{\mathrm{I}}$ ' doğrusal olmayan fonksiyonları Denklem (2c)'deki gibi tanımlanmıştır.

$$
\begin{gathered}
f_{j}(\Theta)=\frac{1}{1-\exp \left(-\alpha_{j}\left(\Theta-\theta_{j}\right)\right.}, \quad j \in[E, I] \\
f_{j}(\Theta)=\tanh (\mu \Theta), \quad j \in[E, I] \\
f_{j}(\Theta)=\eta[|\Theta+1|-|\Theta-1|], \quad j \in[E, I]
\end{gathered}
$$

Buna göre, bahsi geçen iki kümenin orijinde çakışık; fakat doğrultularının farklı olduğu kabulü yapılır [14]. Ortagonallik koşulu gereği, vektörler eksenlerde döndürülse de uzunlukları sabit kalmalıdır. İki bileşenle tanımlanabilen bir vektörün bileşenlerinin rotasyon işlemi sonrasındaki tanımlamaları aşağıdaki gibidir:

$$
\begin{aligned}
& \hat{x}=x \cos \theta-y \sin \theta \\
& \hat{y}=x \sin \theta+y \cos \theta
\end{aligned}
$$

Rotasyon işleminin doğrusal karakteristiği sayesinde alternatif kümeler arasındaki dönüşüm matrissel bir formda tanımlanabilir ( $\hat{x}=R x)$. Burada ' $\mathrm{R}$ ' rotasyon matrisidir ve Denklem (4)'teki gibi tanımlanmaktadır:

$$
\left[\begin{array}{l}
\hat{x} \\
\hat{y}
\end{array}\right]=\overbrace{\left[\begin{array}{rr}
\cos \theta & -\sin \theta \\
\sin \theta & \cos \theta
\end{array}\right]}^{R}\left[\begin{array}{l}
x \\
y
\end{array}\right]
$$

Burada Denklem (1)'deki 'W-C' nöron modelinin ' $E$ ' durum değişkeni ' $x$ ' ve 'I' durum değişkeni ' $y$ ' parametresi gibi düşünülerek Denklem (4)'e adapte edilebilir. Burada matrissel çarpma işlemi sonucunda Denklem (5)' teki ifade elde edilir:

$$
\begin{aligned}
\dot{\hat{E}}= & \cos \theta\left[\left(-E+f_{E}\left(c_{E E} E-c_{I E} I+P\right)\right) / \tau_{E}\right] \\
& -\sin \theta\left[\left(-I+f_{I}\left(c_{E I} E-c_{I I} I+Q\right)\right) / \tau_{I}\right] \\
\dot{\hat{I}}= & \sin \theta\left[\left(-E+f_{E}\left(c_{E E} E-c_{I E} I+P\right)\right) / \tau_{E}\right] \\
& \left.+\cos \theta\left[-I+f_{I}\left(c_{E I} E-c_{I I} I+Q\right)\right) / \tau_{I}\right]
\end{aligned}
$$

Denklem (5)'te rotasyon matrisinin tersi alınarak ( $\left.x=R^{\prime} \hat{x}\right)$ bir düzenleme yapılırsa;

$$
\begin{aligned}
& T_{1}=E=\hat{E} \cos \theta+\hat{I} \sin \theta \\
& T_{2}=I=-\hat{E} \sin \theta+\hat{I} \cos \theta
\end{aligned}
$$

elde edilir ve buna göre Denklem (5) yeniden düzenlenerek, Denklem (7)'deki rotasyon kontrollü W-C nöron modeli tanımlaması türetilebilir:

$$
\begin{aligned}
\dot{\hat{E}}= & \cos \theta\left[\left(-T_{1}+f_{E}\left(c_{E E} T_{1}-c_{I E} T_{2}+P\right)\right) / \tau_{E}\right] \\
& -\sin \theta\left[\left(-T_{2}+f_{I}\left(c_{E I} T_{1}-c_{I I} T_{2}+Q\right)\right) / \tau_{I}\right] \\
\dot{\hat{I}}= & \sin \theta\left[\left(-T_{1}+f_{E}\left(c_{E E} T_{1}-c_{I E} T_{2}+P\right)\right) / \tau_{E}\right] \\
& +\cos \theta\left[\left(-T_{2}+f_{I}\left(c_{E I} T_{1}-c_{I I} T_{2}+Q\right)\right) / \tau_{I}\right]
\end{aligned}
$$

Bu tanımlamada $\theta=[0,45,90,135,180,225,270,315]$ derece değerleri için yapılan ve W-C nöron modeli durum değişkenlerinin belirtilen açı değerlerindeki faz portresi gösterimlerinin birbiri üzerine çizdirilmesi ile elde edilen nümerik simülasyon sonucu Şekil 3 'te sunulmuştur. Bu gösterimlerden elde edilen sonuçlara göre; $\theta=[0,45,90$, 135] açı değerlerinde elde edilen faz portreleri (Şekil 3.a) sirasiyla $\theta=[180,225,270,315]$ derecelerinde elde edilen faz portreleri (Şekil 3.b) ile aynıdır. Bu sebeple sekiz farklı açı değeri için simülasyon yapılmasına rağmen, dört farklı konumda faz portresi elde edilmiştir.

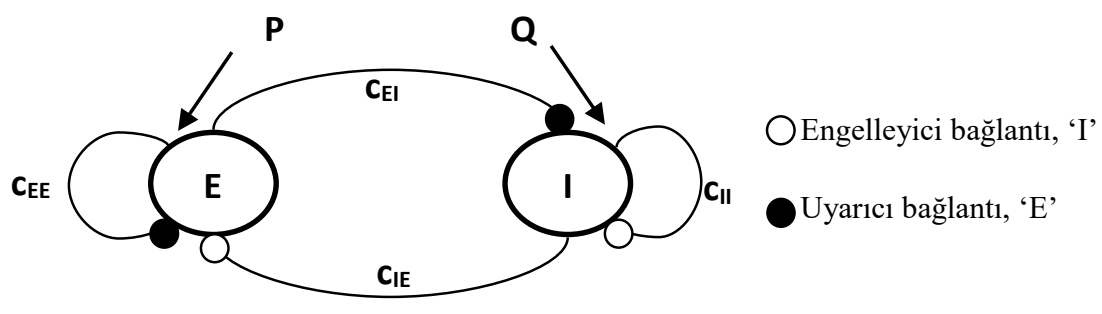

Şekil 1. Wilson-Cowan nöron modelinin genel özelliklerini temsil eden şematik bir gösterim. 


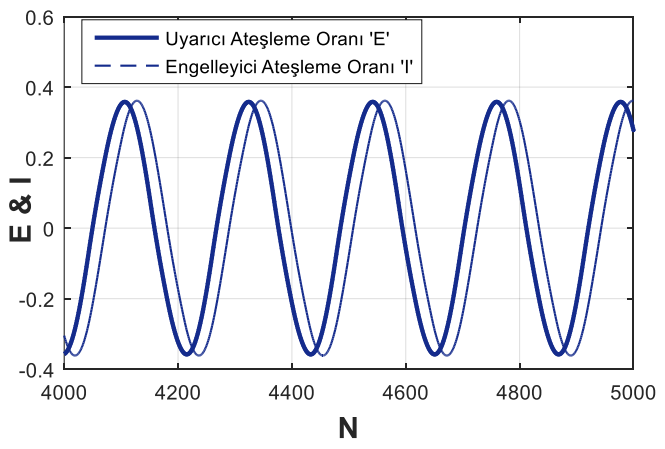

(a)

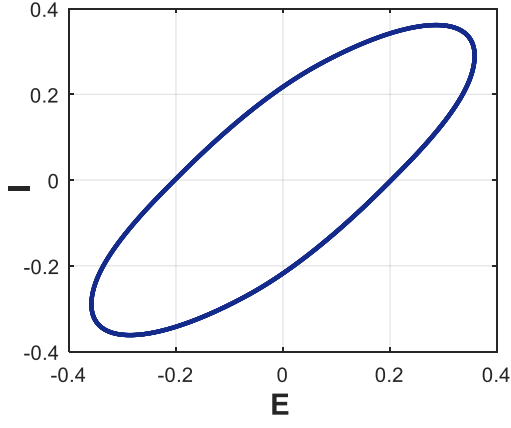

(b)

Şekil 2. Wilson-Cowan nöron modelinin nümerik simülasyon sonuçları: a) 'E' ve 'I' durum değişkenlerinin zaman domeni cevapları, b) Bu dinamiklerin faz portreleri.

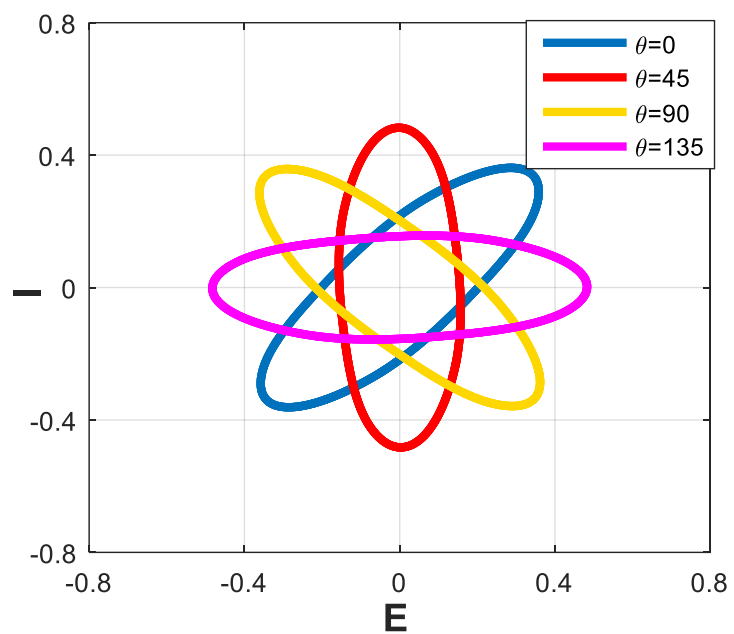

(a)

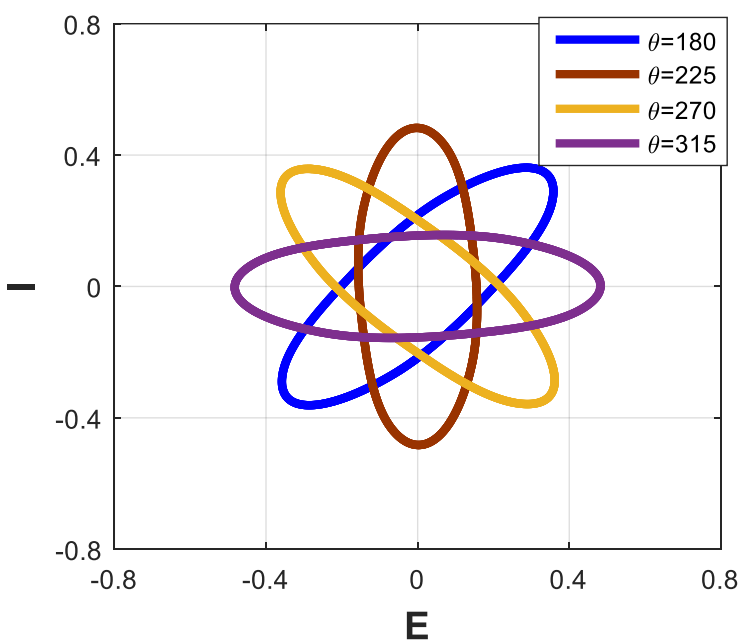

(b)

Şekil 3. Rotasyon kontrollü W-C nöron modelinin; a) $\theta=[0,45,90,135]$ açı değerleri, b) $\theta=[180,225,270,315]$ açı değerleri için faz portresi gösterimleri.

\section{Rotasyon kontrollü W-C Nöron modelinin FPGA tabanlı gerçekleştirimi}

Biyolojiden esinlenilerek tasarlanan sistemlerin donanım gerçekleştirimi çalışmalarında kullanılan elektronik ekipmanın; düşük güç ve alan tüketimi, farklı tasarımların ilave süreçlere ihtiyaç duyulmaksızın denenmesine imkan sağlama ve hızlı prototiplendirme gibi özelliklere sahip olması en çok tercih edilen özelliklerden bazılarıdır. Doğrusal olmayan sistemlerin rotasyon kontrolünün donanım doğrulaması ile desteklendiği çalışmalarda, malzeme temini ve pratik gerçekleştirim açısından avantaj sağlayan ayrık elemanlarla gerçekleştirim çalışmaları literatürde mevcutken, yukarıda bahsedilen özelliklerin pek çoğunu bir arada bulunduran programlanabilir ve yeniden yapılandırılabilir analog/dijital donanımların kullanıldığı çalışmalar da son yıllarda dikkat çekmektedir [12, 13, 15]. $\mathrm{Bu}$ çalışmada rotasyon kontrollü $\mathrm{W}-\mathrm{C}$ nöron modelinin donanım gerçekleştirimi için; yukarıda bahsedilen özelliklere ilaveten paralel çalışma prosedürüne de sahip olan ve pek çok araştırmanın prototip gerçekleştirimi için tercih edilen alan programlanabilir kapı elemanı (FPGA) kullanılmıştır. FPGA elemanı programlanabilirlik ve yeniden yapılandırılabilirlik özelliklerine sahip olan, paralel çalışma prosedürü ile işleyen ve dijital özellikte olan bir elektronik ekipmandır. Bu sebeple, bu çalışmada ele alınan ve diferansiyel denklemlerle tanımlanan rotasyon kontrollü W-C sisteminin FPGA tabanlı gerçekleştirimi için; ilgili sistem ayrık zamanlı bir ifadeye dönüştürülmelidir. Burada bu dönüşüm işlemi için, önceki bölümlerde de bahsedildiği gibi Euler ayrıklaştırma yöntemi kullanılmış ve adım büyüklüğü $\Delta \mathrm{h}=0.01$ olarak ayarlanmıştır. Denklem (7)'deki sisteme ayrıklaştırma yöntemi uygulandıktan sonra elde edilen nihai tanımlama Denklem (8)'de verilmektedir:

$$
\begin{aligned}
\hat{E}_{n+1}= & \left\{\cos \theta\left[\left(-T_{1}+f_{E}\left(c_{E E} T_{1}-c_{I E} T_{2}+P\right)\right) / \tau_{E}\right]\right. \\
& \left.-\sin \theta\left[\left(-T_{2}+f_{I}\left(c_{E I} T_{1}-c_{I I} T_{2}+Q\right)\right) / \tau_{I}\right]\right\} \\
& \Delta h+\hat{E}_{n} \\
\hat{I}_{n+1}=\{ & \sin \theta\left[\left(-T_{1}+f_{E}\left(c_{E E} T_{1}-c_{I E} T_{2}+P\right)\right) / \tau_{E}\right] \\
& \left.+\cos \theta\left[\left(-T_{2}+f_{I}\left(c_{E I} T_{1}-c_{I I} T_{2}+Q\right)\right) / \tau_{I}\right]\right\} \\
& \Delta h+\hat{I}_{n}
\end{aligned}
$$


Denklem (8) ile tanımlanan rotasyon kontrollü W-C nöron modelinin FPGA tabanlı gerçekleştirimi için "DSP'ler için Sistem Üreteci (System Generator for DSP-XILINX ${ }^{\mathrm{TM}}$ SG $\left.{ }_{D S P}\right)$ " programı kullanılmıştır. Bu program MATLABSIMULINK $^{\mathrm{TM}}$ programı ile XILINX ${ }^{\mathrm{TM}}$ tarafindan sağlanan kodlar arasında otomatik dönüşüm imkânı sağlamaktadır. MATLAB-SIMULINK ${ }^{\mathrm{TM}}$ üzerinde oluşturulan sistem, dönüşüm işleminin ardından doğrudan XILINX ${ }^{\mathrm{TM}}$ tarafından üretilen FPGA donanımına gömülebilmektedir [22]. Şekil 4'te rotasyon kontrollü $\mathrm{W}-\mathrm{C}$ nöron modeli için $\mathrm{SG}_{\mathrm{DSP}}$ arac1 ile tasarlanmış bir şema görülmektedir. Bu şemada $\theta=[0$, $45,90,135]$ açı değerleri için hesaplamalar ayrı ayrı yapılmış dolayısı ile sonuçlar da ayrı ayrı kaydedilmiştir. Tasarımda $\mathrm{Q}(32,18)$ bit sabit noktalı aritmetik kullanılmış ve otomatik dönüşüm sonrası elde edilen kodlar XILINXTM firmasının SPARTAN-3AN geliştirme kartına gömülmüştür. Bu kart üzerinde dâhili bir dijital-analog dönüştürücü (LTC2624) bulunmaktadır. Şekil 5 'te sunulan rotasyon kontrollü W-C nöron modelinin $\theta=[0,45,90,135]$ açı değerlerinde yapılan ölçümleri için elde edilen sonuçlar, bahsedilen dijital-analog dönüştürücü kullanılarak kaydedilmiştir. Şekil 5'te kullanılan osiloskopun, desenleri üst üste çizdirme fonksiyonundan yararlanılarak ölçülen $\theta=[0,45,90,135]$ değerleri için faz portresi gösterimleri görülmektedir. Bu gösterim Şekil 3 'teki nümerik simülasyon sonucu elde edilen desenle oldukça benzerdir. Bu benzerlikten de görüleceği gibi, rotasyon kontrollü W-C nöron modelinin FPGA tabanlı donanım gerçekleştirimi başarılı bir şekilde sonuçlandırılmıştır. $\mathrm{Bu}$ gerçekleştirimlerden $\theta=45$ derece için yapılan FPGA tabanlı gerçekleştirim çalışmasında, tasarlanan yapıya ait bazı sentez sonuçları Tablo 1'de sunulmaktadir.

Tablo 1. Rotasyon Kontrollü W-C nöron modelinin FPGA tabanlı gerçekleştirimindeki alan kullanımı ve sentez sonuçları

$\begin{array}{lc}11777 \text { adet } & 108(\% 1) \\ \text { REGISTER'da kullanılan sayısı } & 2963(\% 23) \\ 11777 \text { adet } & \\ 4 \text { giriş LUT'ta kullanılan sayısı } & \\ 5888 \text { adet } & 3229(\% 27) \\ \text { SLICE'ta kullanılan sayısı } & \\ 24 \text { Adet BUFGMUX'ta kullanılan sayısı } & 2(\% 8) \\ & \\ \text { 20 Adet } & \\ \text { MULT18X18SIO'da kullanılan sayısı } & 0(\% 0) \\ \text { Maksimum gecikme (ns) } & 1.060\end{array}$

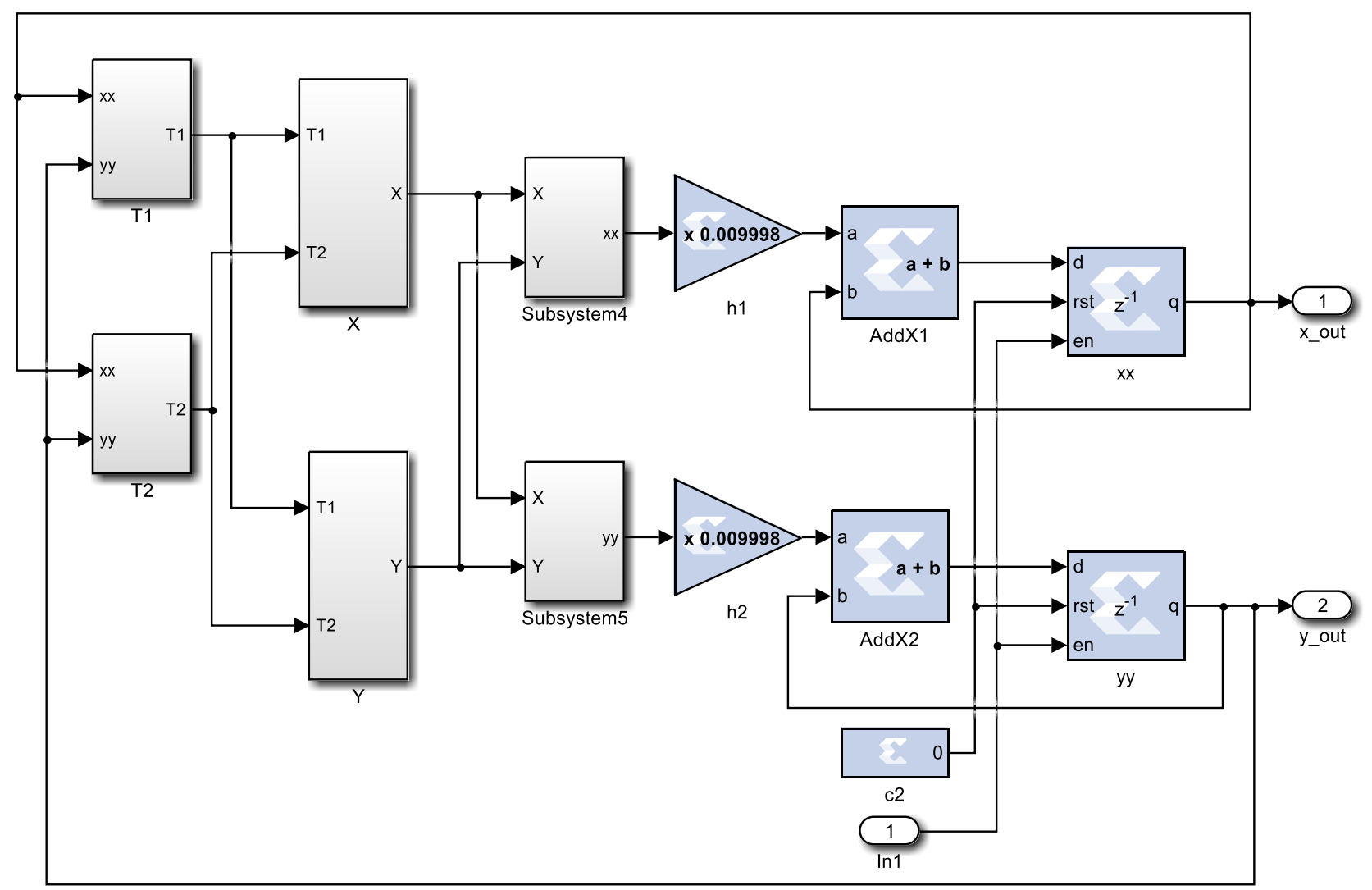

Şekil 4. Rotasyon kontrollü W-C nöron modeli için SGDSP aracı ile tasarlanmış bir şema. 


\section{Sonuçlar}

$\mathrm{Bu}$ çalışmada uyarıcı ve engelleyici nöron popülasyonları arasındaki etkileşimi açıklama açısından öne çıkan WilsonCowan nöron modelinin dinamik çeker yapısının rotasyon dönüşüm işlemi ile kontrol edilebilirliği üzerinde durulmuştur. W-C nöron modelinin tanıtılması, nümerik simülasyonunun yapılmasının ardından, modele rotasyon dönüşüm işlemleri başarılı bir şekilde uygulanmıș ve modelin çeker yapısının faz kontrolü başarılı bir şekilde sağlanmıştır. Faz kontrolünün etkiliğinin görülmesi için açı

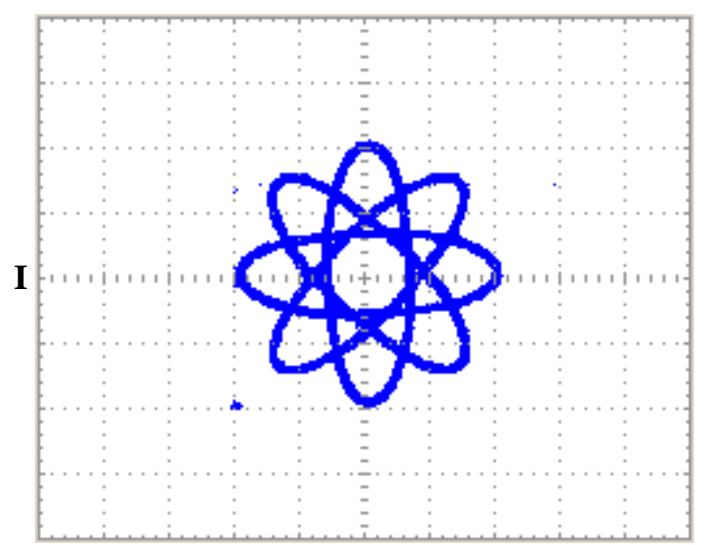

E (a) değerleri [0-360] derece aralığında 45 'er (kırk beş) derece adımlarla değiştirilmiş ve bu açı değerlerinde $\mathrm{W}$-C nöron modelinin dinamik çeker rotasyonu gözlemlenmiştir. Ardından, takip edilen prosedürün donanım gerçekleştirim uygulamalarına adapte edilebilirliğinin gösterilmesi amacı ile rotasyon kontrollü W-C nöron modelinin FPGA elemanı ile gerçekleștirimi yapılmıștır. Gerçekleştirim sürecinde "System Generator for DSP" aracından yararlanılmıştır. Kaydedilen deneysel sonuçlar, rotasyon kontrollü bir sistemin FPGA donanımı ile başarılı bir șekilde gerçeklenebileceğini göstermektedir.

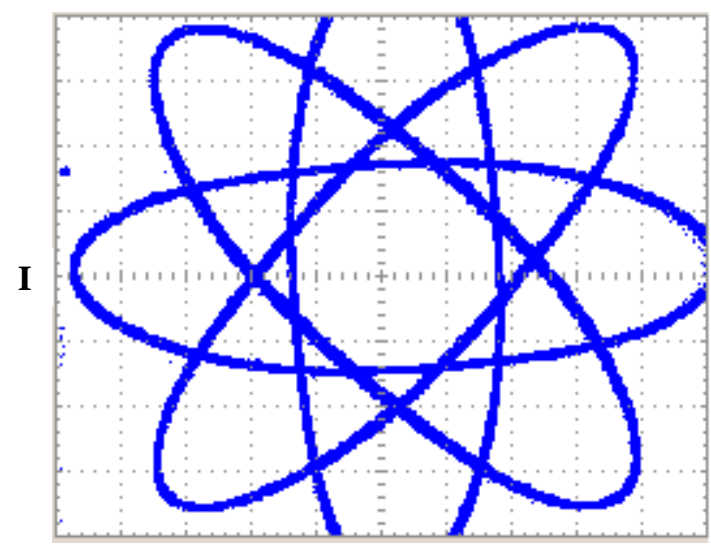

$\mathbf{E}$

(b)

Şekil 5. Rotasyon kontrollü W-C nöron modelinin FPGA tabanlı gerçekleştirimi ile $\theta=[0,45,90,135]$ değerleri için elde edilen faz portresi gösterimleri: a) $\mathrm{x}=\mathrm{y}=500 \mathrm{mV} / \mathrm{div}$, b) $\mathrm{x}=\mathrm{y}=200 \mathrm{mV} / \mathrm{div}$.

\section{Çıkar çatışması}

Yazarlar çıkar çatışması olmadığını beyan etmektedir.

\section{Benzerlik oranı (iThenticate): $\% 10$}

\section{Kaynaklar}

[1] E. R. Kandel, J. H. Schwartz ve T. M. Jessell, Principles of Neural Science. 4th ed. McGraw-Hill, New York. ISBN 0- 8385-7701-6, 2000.

[2] A. L. Hodgkin ve A. F. Huxley, A quantitative description of membrane current and its application to conduction and excitation in nevre. The Journal of Physiology, 117(4), 500-544, 1952. https://doi.org/ 10.1113/ jphysiol .1952 .sp004764

[3] R. FitzHugh, Mathematical models for excitation and propagation in nerve. In: Schawn, H.P. (ed.) Biological Engineering, vol. 1, pp. 1-85. McGraw-Hill, New York, 1969.

[4] J. L. Hindmarsh ve R. M. Rose, A model of neural bursting using three couple first order differential equations. Proceedings of the Royal Society B: Biological Sciences, 221(1222), 87-102, 1984. https://doi.org/10.1098/rspb.1984.0024

[5] E. M. Izhikevich, Simple model of spiking neurons. IEEE Transactions on Neural Networks and Learning
Systems, 14(6), 1569-1572, 2003. https://doi.org/ 10.1109/tnn.2003.820440

[6] H. R. Wilson ve J. D. Cowan, Excitatory and inhibitory interactions in localized populations of model neurons. Biophysical Journal, 12 (1), 1-24, 1972. https://doi.org/10.1016/ S0006-3495(72)86068-5

[7] M. Bertalmío ve J. D Cowan, Implementing the Retinex algorithm with Wilson-Cowan equations. Journal of Physiology - Paris, 103(1-2), 69-72, 2009. https://doi.org/ 10.1016/j.jphysparis.2009.05.001

[8] X. Lin, S. Zhou, Li, H. Tang ve Y. Qi, Rhythm oscillation in fractional order Relaxation oscillator and its application in image enhancement. Journal of Computational and Applied Mathematics, 339, 69-84, 2018. https://doi.org/10.1016/ j.cam.2018.01.027

[9] C. M. Pinto ve A. P. Santos, Modelling gait transition in two-legged animals. Communications in Nonlinear Science and Numerical Simulation, 16(12), 46254631, 2011. https://doi.org/10.1016/j.cnsns.2011. 05.033

[10] L. M. Pecora ve T. L. Carroll, Synchronization in chaotic systems. Physical Review Letters, 64(8), 821, 1990. https://doi.org/10.1063/1.4917383

[11] S. K. Bhowmick, B. K. Bera ve D. Ghosh, Generalized counter-rotating oscillators: mixed synchronization. 
Communications in Nonlinear Science and Numerical Simulation, 22(1-3), 692-701, 2015. https://doi.org/ 10.1016/j.cnsns.2014.09.024

[12] A. Sharma, M. Dev Shrimali ve S. Kumar Dana, Phaseflip transition in nonlinear oscillators coupled by dynamic environment. Chaos, 22(2), 023147, 2012. https://doi.org/10.1063/1.4729459

[13] A. Prasad, S. K. Dana, R. Karnatak, J. Kurths, B. Blasius ve R. Ramaswamy, Universal occurrence of the phase-flip bifurcation in time-delay coupled systems. Chaos, 18(2), 023111, 2008. https://doi.org/10.1063/ 1.2905146

[14] G. B. Arfken, H. J. Weber, Mathematical methods for physicists. 6th edn. Elsevier Academic Press, Cambridge. ISBN 0-12-088584-0, 1999.

[15] N. Korkmaz, A Phase Control Method for the Dynamical Attractor of the HR Neuron Model: The Rotation-Transition Process and Its Experimental Realization. Neural Processing Letters, 53, 3877-3892, 2021. https://doi.org/10 .1007/s11063-021-10568-w

[16] H. R. Wilson ve J. D Cowan, A mathematical theory of the functional dynamics of cortical and thalamic nervous tissue, Kybernetik, 13(2), 55-80, 1973. https://doi.org/10.1007/BF00288786
[17] H. R. Wilson, Spikes, decisions, and actions: the dynamical foundations of neuroscience, Oxford University Press, 1999.

[18] E. Negahbani, D. A. Steyn-Ross, M. L. Steyn-Ross, M. T. Wilson ve J. W. Sleigh, Noise-induced precursors of state transitions in the stochastic Wilson-Cowan model. The Journal of Mathematical Neuroscience (JMN), 5(1), 1-27, 2015. https://doi.org/10.1186/ s13408-015-0021-X

[19] S. Ahmadizadeh, D. Nešić, D. R. Freestone ve D. B. Grayden, On synchronization of networks of WilsonCowan oscillators with diffusive coupling. Automatica, 71, 169-178, 2016. https://doi.org/10.1016/j.automati ca .2016 .04 .030

[20] J. D. Cowan, J. Neuman ve W. Van Drongelen, Wilson-Cowan equations for neocortical Dynamics. The Journal of Mathematical Neuroscience, 6(1), 1-24, 2016. https://doi.org/10.1186/s13408-015-0034-5

[21] P. J. Srinidhi, T. R. Yashaswini, N. Uttunga, S. A Ali ve M. R. Ahmed, Implementation of STDP based learning rule in neuromorphic CMOS circuits. In IEEE 2017 International Conference on Intelligent Computing and Control Systems (ICICCS), 11051110, Madurai, India, June 2017. doi: 10.1109/1ccons.2017.8250637

[22] www.xilinx.com, Date of access: 28.09.2021. 